\title{
Effects of leaf removal on aromatic precursor dynamics during maturation of Ribolla Gialla grapes (Vitis vinifera L.)
} \author{
and Paolo Sivilotti ${ }^{1}$ \\ ${ }^{1}$ Department of Agricultural, Food, Environmental and Animal Sciences, University of Udine, Italy \\ ${ }^{2}$ Perleuve s.r.l., Gorizia, Italy \\ ${ }^{3}$ Bertani domains s.r.l., Grezzana, Italy
}

Sabrina Voce ${ }^{1}$, Giulia Pizzamiglio ${ }^{1}$, Davide Mosetti $^{2}$, Giovanni Bigot ${ }^{2}$, Andrea Lonardi ${ }^{3}$, Piergiorgio Comuzzo ${ }^{1}$

\begin{abstract}
Leaf removal is a viticultural practice applied in order to improve fruit-zone microclimate and berry quality. The aim of this trial was to evaluate the effect of post-flowering leaf removal on maturation and biosynthesis of terpenes and and $\mathrm{C}_{13}$-norisoprenoids in Ribolla Gialla grapes. In the seasons 2015 and 2016, basic maturation parameters were nearly unaffected by leaf removal. Contrarily, in the second season, 2016, one week before harvest, the concentration of several aroma compounds was significantly improved by leaf removal. In conclusion, the trial here showed that leaf removal improves the concentration of aroma compounds in the grapes, but the selection of the date of harvest is more crucial in order to maintain them during vinification.
\end{abstract}

\section{Introduction}

Aroma compounds in grapes are found as glycosylated precursors and, during alcoholic fermentation, they are released, contributing to the varietal aroma of wine. They are produced during berry ripening by different biosynthetic pathways [1-3] and their concentration depends on a combination of different factors.

Concerning canopy management, leaf removal around flowering is widely used to improve fruit-zone microclimate, reduce rot infections and allow a better grape maturation [4]. In regards to secondary metabolites, many experiments revealed positive effects of such techniques on polyphenols [5-9], while few reports are available about the effects on aroma compounds [10-13].

Ribolla Gialla is an autochthonous grape variety widespread in Friuli Venezia Giulia (North East Italy) and in western Slovenia. Because of the limited interest that such varieties attracted in the past, little information is available in the international literature databases [14-15].

Thus, the aim of this work was to evaluate the effect of leaf removal applied in post-flowering stage on basic maturation parameters and on the potential aromatic profile of Ribolla Gialla grapes during ripening and at harvest.

\section{Material and methods}

\subsection{Location, experimental plot and sampling}

The experimental trials were carried out in 2015 and 2016 in a vineyard of $V$. vinifera cv. Ribolla Gialla located in Romans d'Isonzo (North-Eastern Italy) and owned by Bertani domains s.r.l. Planted in 2009, the vineyard had a density of 5000 plants/ha $(2.5 \mathrm{~m}$ between rows and $0.8 \mathrm{~m}$ between vines) and the vines were Guyot trained.

The soil of that area is characterized by Isonzo river alluvial deposits ( $26 \%$ clay, $29 \%$ sand, $28 \%$ coarse), classified as Rhodi Cambisol Endoskeletic.

Local meteorological data was obtained from the OSMER website (http://omnia.meteo.fvg.it/).

For the purpose of the study, six adjacent rows were selected and two main plots of three rows arranged. Two treatments were compared: UNT, untreated vines and LR, mechanical leaf removal applied at berry-set. Berry set was recorded on $8^{\text {th }}$ June 2015 and $10^{\text {th }}$ June 2016, and véraison on 12 Aug 2015 and 16 Aug 2016, respectively. Within each main plot, three replicates of 30 vines were selected on two contiguous rows in order to be more representative. As for leaf removal, a pulsed air leaf remover was used (Olmi S.n.c., Asti, Italy), and ca $20-25 \%$ leaves were removed.

Form veraison until harvest, 300-berry samples were collected from each plot, and stored in a portable fridge until arrival in the laboratory. Each sample was divided in two aliquots of 150 berries; the firstwas 
frozen in liquid nitrogen and stored at $-20^{\circ} \mathrm{C}$ for aroma analysis, while the remaining sample was used for the evaluation of basic maturation parameters: total soluble solids (TSS), titratable acidity, $\mathrm{pH}$ and berry weight.

\subsection{Volatile profile extraction}

Aroma compounds were determined by a modified version of the method reported by Comuzzo et al. [16]. Berries were completely mashed in a kitchen blender, in presence of $0.30 \mathrm{~g}$ of ascorbic acid (added to avoid oxidation). Samples were then centrifuged at $5000 \mathrm{rpm}$ for $3 \mathrm{~min}$ and the supernatant was paper-filtered. An aliquot of $50 \mathrm{~mL}$ (100 mL in [16]) of filtered juice was transferred in a volumetric flask; $25 \mu \mathrm{L}$ of 1-heptanol $(493 \mu \mathrm{g} / \mathrm{mL}$, in ethanol $96 \% \mathrm{v} / \mathrm{v})$ was added as internal standard (100 $\mu \mathrm{L}$ of 1-heptanol, $500 \mu \mathrm{g} / \mathrm{mL}$ in [16]). Samples were loaded onto Isolute ${ }^{\circledR} 500 \mathrm{mg}, 6 \mathrm{~mL}$, C18 SPE cartridges (Biotage, Uppsala, Sweden), previously conditioned with $25 \mathrm{~mL}$ of methanol and 25 $\mathrm{mL}$ of Milli-Q grade water. After loading, a washing step was carried out with $150 \mathrm{~mL}$ of Milli-Q water. Free terpenes and norisoprenoids were then eluted with $25 \mathrm{~mL}$ of pentane:dichloromethane $(2: 1 \mathrm{v} / \mathrm{v})$. The eluate was dehydrated with anhydrous sodium sulfate and stored at $-20{ }^{\circ} \mathrm{C}$ until GC-MS analysis.

Bound varietal aromas were eluted from the same cartridge with $25 \mathrm{~mL}$ of methanol. The eluate was collected in conical tubes and evaporated in a vacuum centrifuge (Univapo 100H; Uniequip, Planegg, Germany). The residue was resuspended in $5 \mathrm{~mL}$ of 0.2 $\mathrm{M}$ citrate buffer ( $\mathrm{pH}$ 5) and treated with $200 \mu \mathrm{L}$ of glycosidase preparation (Rapidase Revelation Aroma, Oenobrands SAS, Montpellier, France, $25 \mathrm{~g} / \mathrm{L}$ in Milli$\mathrm{Q}$ grade water). The samples were conditioned at $40{ }^{\circ} \mathrm{C}$ for $20 \mathrm{~h}$ to allow enzymatic hydrolysis, transferred into a $10 \mathrm{~mL}$ volumetric flask and supplemented with $25 \mu \mathrm{L}$ of 1-heptanol solution. Bound terpenes and norisoprenoids were extracted three times with $2.5 \mathrm{~mL}$ of pentane:dichloromethane $(2: 1 \mathrm{v} / \mathrm{v})$, after addition of $5 \mathrm{~mL}$ of $30 \%(\mathrm{w} / \mathrm{v})$ sodium chloride solution [16]. The organic phase was collected in a pyrex tube, dehydrated with anhydrous sodium sulfate and concentrated under nitrogen flow to a final volume of approximately $1 \mathrm{~mL}$. The samples obtained were subjected to GC-MS analysis, as detailed below.

\subsection{GC-MS analysis}

The system used for GC-MS analyses was a GC17A gas chromatograph coupled with a QP-5000 mass spectrometer (both by Shimadzu Corporation, Kyoto, Japan). Volatile compounds were separated on a J\&W DB-Wax capillary column $(30 \mathrm{~m} \times 0.25 \mathrm{~mm}$ i.d., $0.25 \mu \mathrm{m}$ film thickness) supplied by Agilent Technologies Inc. (Santa Clara, CA) under the following operating conditions: $40{ }^{\circ} \mathrm{C}$ for $1 \mathrm{~min}, 4{ }^{\circ} \mathrm{C} / \mathrm{min}$ up to $240{ }^{\circ} \mathrm{C}$, held for $15 \mathrm{~min}$. The injection $(1 \mu \mathrm{L})$ was performed in splitless mode, with a splitless time of $60 \mathrm{~s}$. The injector and detector temperatures were both set to 240 ${ }^{\circ} \mathrm{C}$. The carrier gas was helium at a linear flow rate of
$35 \mathrm{~cm} / \mathrm{sec}$. Electron impact mass spectra were recorded at $70 \mathrm{eV}$, and volatile compounds were tentatively identified by comparison of their mass spectra and retention times with those of standard compounds or by comparison of the mass spectrum with those reported in the mass spectrum libraries Wiley 6 and NIST 107 (both supplied by Shimadzu Corporation, Kyoto, Japan). Moreover, the linear retention indices were calculated according to the retention times of $n$ alkanes, and compared with those reported in the literature (detailed in Comuzzo et al. [16]). Semiquantitative analysis was based on the internal standard method, considering a response factor equal to 1.00 .

\subsection{Statistical analysis}

Differences between treatments at each maturation time were evaluated with $t$-test $(*, \mathrm{p}<0.05 ; * *, \mathrm{p}<0.01$; ***, $\mathrm{p}<0.001)$.

\section{Results}

\subsection{Weather condition}

The two season were characterized by different trends in terms of temperature and rainfall (fig. 1).

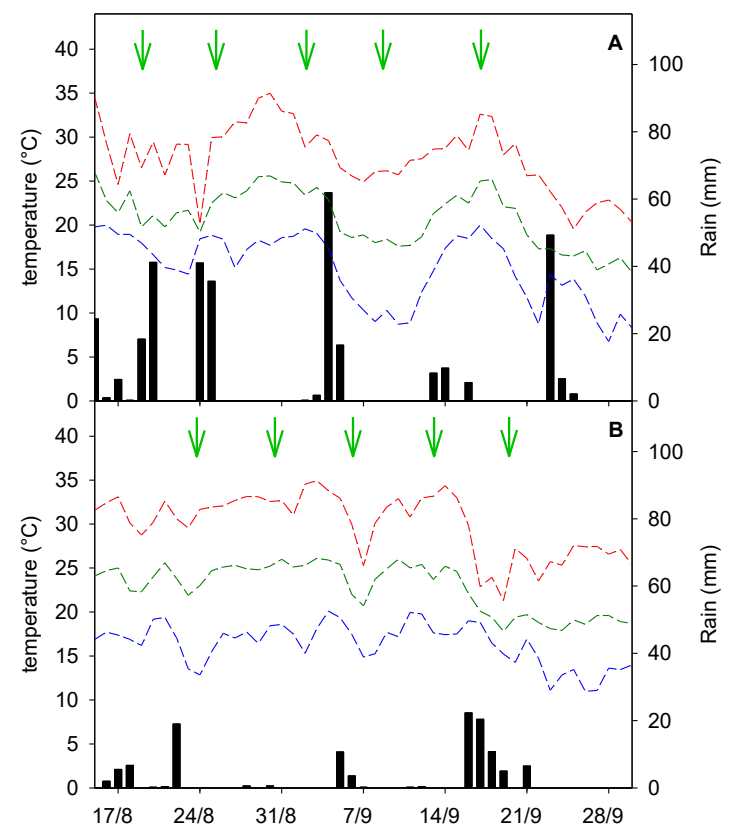

Fig. 1. Trends of temperature and rainfalls in the last part of the seasons 2015 (A) and 2016 (B). Green arrows represent the timing of berry sampling.

In the season 2015, from June on, temperatures were higher compared to the historical values and two peaks were registered at the last ten days of August and at between $10^{\text {th }}$ and $20^{\text {th }}$ of September. Conversely, rain was regularly distributed during the season, avoiding any water stress conditions in the vineyard. In the following season 2016, from July on, the temperature 
was particularly high, exceeding $30{ }^{\circ} \mathrm{C}$ for several days. Considering the same period, rains were much lower than the average. At the time of harvest, GDD accumulated 1900 and $1880{ }^{\circ} \mathrm{C}$ in 2015 and 2016, respectively, thus not only meteorological conditions were responsible for the differences in the observed maturation trends of the grapes.

\subsection{Effect of leaf removal on basic maturation parameters.}

The evolution of berry weight, soluble solids and titratable acidity were slightly affected by leaf removal in both 2015 and 2016 seasons (Fig. 1).

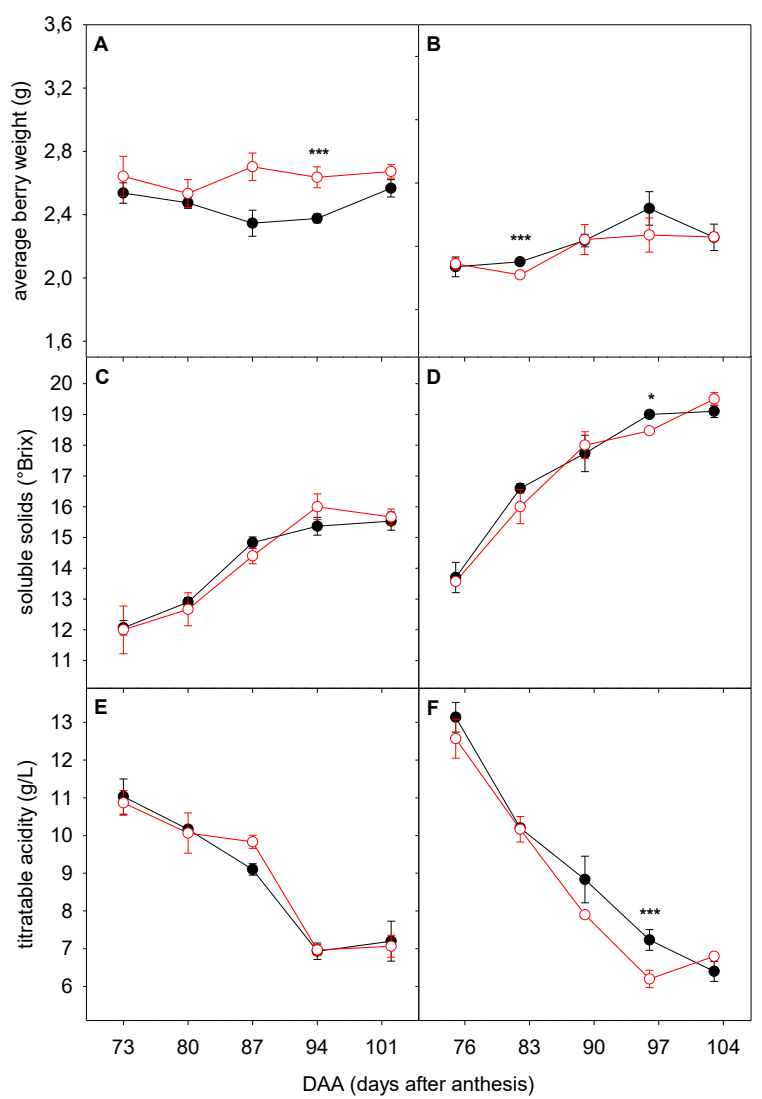

Fig. 2. Trends of berry weight (A,B), soluble solids (C,D) and titratable acidity $(\mathrm{E}, \mathrm{F})$ during maturation in the seasons 2015 (A,C,E) and 2016 (B,D,F). O, LR; ๑, UNT. Data were processed with t-test $(*, p<0.05 ; * * *, p<0.001)$.

In the first year of the trial, the optimal evolution of temperatures and the constant distribution of rain resulted in typical values for maturation parameters of Ribolla Gialla grapes (fig. 2C,E). To the contrary, the high temperatures and the low rain occurred during maturation in the following season (2016) resulted in higher soluble solids and lower titratable acidity (fig. 2D,F). The differences in berry weight, higher in 2015 and lower in 2016, are mostly responsible for the differences in the maturation parameters (Fig. 2A,B). The effect of leaf removal on basic maturation parameters was nearly negligible (a difference only emerged between UNT and LR one week before harvest 2016), proving that the technique poorly affected these parameters.

\subsection{Effect of leaf removal on aroma compounds.}

The aroma compounds of the grapes at harvest 2015 and 2016 were not exactly the same, possibly due to the different maturation levels of the grapes and the particular meteorological trend of the seasons (fig. 3). Furthermore, the differences between UNT and LR were mostly inconsistent, and no significant differences between treatments were found. Only 2,6dimethylocta-3,7-dien-2,6-diol was significantly higher in LR in the season 2016.

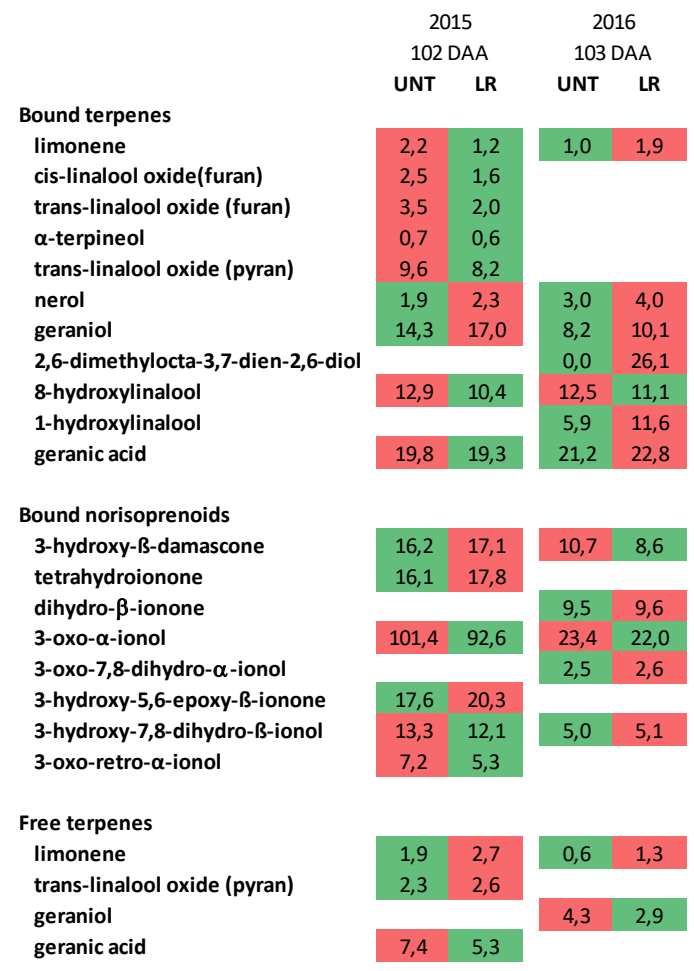

Fig. 3. Concentration of aroma compounds at harvest in the seasons 2015 and 2016 in UNT and LR grape berries. Conditional color formatting was applied for each compound (red, higher values; green, lower values). $t$-test was applied and significant differences (appeared only in 2016) are reported in Fig. 4. UNT, untreated; LR, preflowering leaf removal.

In the 2016 season, aroma precursors were also monitored during maturation (fig. 4). Most of the compounds detected increased in their concentration, reaching a peak between 89 and 93 DAA (days after anthesis). Seven terpenes and five $\mathrm{C}_{13}$-norisopirenoids were detected: nerol, 1-hydroxylinalool, 8hydroxylinalool, 2,6-dimethylocta-3,7-dien-2,6-diol, geranic acid, geraniol and limonene (the last two in both free and bound forms); 3-hydroxy- $\beta$-damascone, dihydro- $\beta$-ionone, 3-oxo- $\alpha$-ionol, 3-oxo-7,8-dihydro$\alpha$-ionol (blumenol $C$ ) and 3-hydroxy-7,8-dihydro- $\beta$ ionol. 
Most of terpene precursors showed significant differences between UNT and LR on 93 DAA, while on the following date, the concentration of most compounds was similar for the two treatments. Similar behavior was observed for $\mathrm{C}_{13}$-norisoprenoids: considering the average values, their concentration was higher in LR than in UNT, but no significant differences were found. Also, no differences were found in free terpenes. After $6^{\text {th }}$ Sep, the concentration of most aroma compounds dropped.

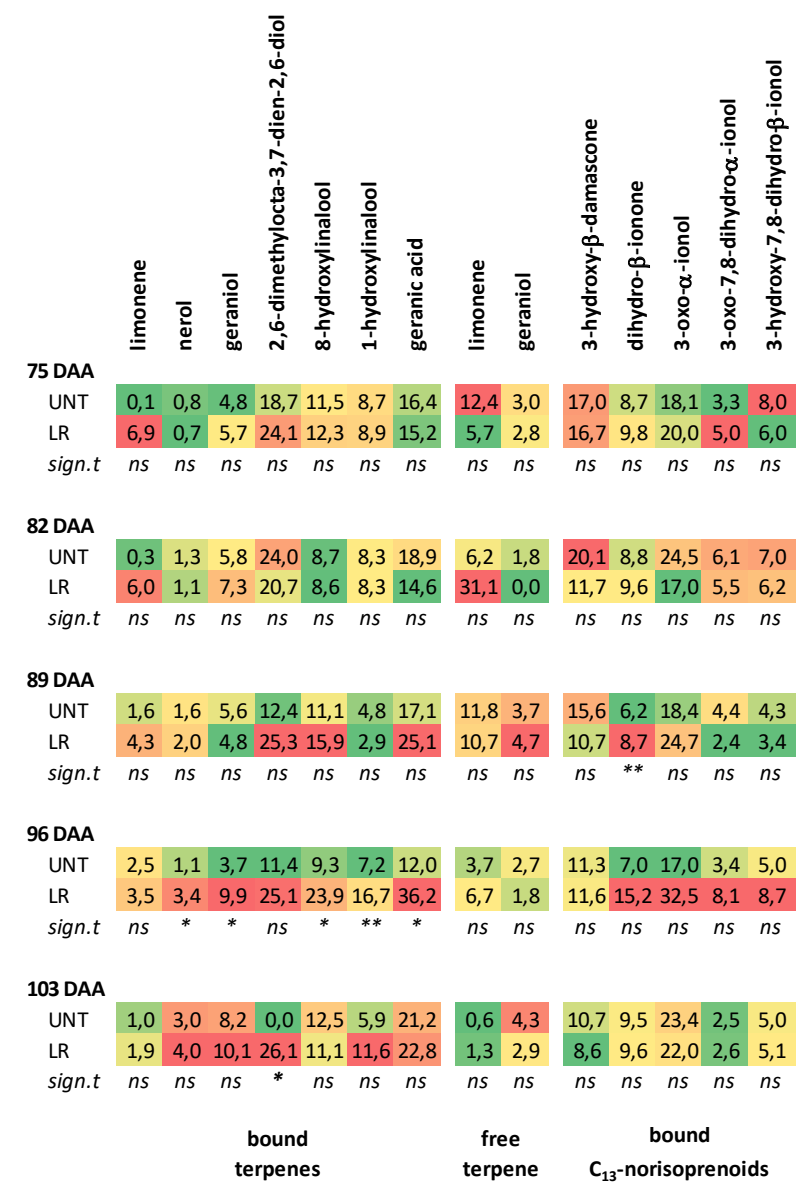

Fig. 4. Concentration of aroma compounds during maturation in the seasons 2016 as affected by leaf removal. Conditional color formatting was applied per each compound: red, higher values; green, lower values. $t$-test was applied to test the significance of differences between treatments (framed cells with bold values) at each date. UNT, untreated; LR, preflowering leaf removal.

\section{Discussion}

Leaf removal is a viticultural practice applied with the aim of improving cluster microclimate, reducing the occurrence of cluster rots, and promoting the accumulation of sugars and secondary metabolites in the berries. In recent years, Sternad Lemut et al. [8] and Sivilotti et al. [12] showed that leaf removal does not improve the accumulation of soluble solids and the degradation of acids, in agreement with the results found in the current study. Assessing the results shown in fig. 2 (A and B), a larger impact of the weather can be observed between the two seasons, as shown by
Sivilotti et al. [12] and Frioni et al. [17]. To date, in the 2016 season, the maturation of grapes occurred during a period of intense water stress, and so berry growth was highly affected (Fig. 2B). The reduction in berry weight then positively influenced the accumulation of soluble solids and the degradation of acids[18].

When leaf area-to-yield ratio falls in the equilibrium range [19], there are negligible effects of canopy management techniques on the technological maturation parameters, but secondary metabolism can be deeply decoupled [20]. Sternad Lemut et al. [8], Šuklje et al. [21] and Sivilotti et al. [12] in their experiments showed that the modification of leaf areato-yield ratio was effective in causing an increase of flavanols and anthocyanins, thiols and thiol precursors, respectively.

Secondary metabolites in grapes accumulate in response to different factors, such as weather conditions, rot infection, water stress, sunlight exposure, etc. Among metabolites, the occurrence of terpenes and $\mathrm{C}_{13}$-norisoprenoids in response to leaf removal treatment were little studied until now $[13,22-$ 23].

By comparing the two seasons (fig. 3), inconsistent effects of leaf removal were observed, possibly due to both differences in weather conditions during harvest and level of grape maturation at harvest. Moreover, we should also consider the important effect of water stress in 2016, known to promote the biosynthesis of secondary metabolites $[13,24]$.

Focusing on trends of volatile compounds, in the season 2016 (fig. 4), free terpenes increased throughout maturation, in agreement with other reports [25-26]. Differently, Zhang et al. [27] observed that the highest concentration in free terpenes was at pre-veraison, assuming that the post-veraison to harvest period is the time at which conversion of precursors into the related aroma compounds occurs. These considerations could help to explain why free geraniol and limonene peaked on 89 DAA and 82 DAA in LR grapes. In regards to bound terpenes, their concentration increased during ripening and reached a maximum on $13^{\text {th }}$ Sep; nerol, geraniol, 1-hydroxylinalool, 8-hydroxylinalool and geranic acid showed highest values in LR grapes, and significant differences between treatments were revealed. At harvest, only 2,6-dimethylocta-3,7-dien2,6-diol concentration was significantly higher in treated vines.

Regarding $\mathrm{C}_{13}$-norisoprenoids, higher sunlight exposure also enhances the synthesis of glycosidic precursors, leading to an increase in aglycone concentration in berries, especially from early fruit formation until veraison [28]. The trend observed in our experiment was inconsistent for most of the compounds analyzed; regardless, for most terpenes and $\mathrm{C}_{13}$-norisoprenoids in bound form, a maximum concentration was shown on $13^{\text {th }} \mathrm{Sep}$, with the highest amounts of these compounds in the LR grapes. The higher sunlight exposure caused by leaf removal could promote the biosynthesis of varietal aroma compounds and their glycosidic precursors, confirming the results provided by other authors $[13,22,27,29]$. 
At harvest, the concentration decreased, possibly due to an over-ripening process that caused a degradation of both free and bound aroma compounds.

In summary, leaf removal can be considered as a positive viticultural technique that can be applied also on Ribolla Gialla, to improve cluster microclimate, reduce rot infection and improve the quality characteristics of the grapes. In our experiment, positive effects of the technique were shown also for the accumulation of aroma precursors in grapes. We already highlighted in the introduction that Ribolla Gialla has a poor aroma background and every technique capable of improving their quality and presence would be embraced by growers, winemakers, and consumers alike. In any case, particular care should be dedicated to the maturation time in order to avoid losses of such components caused by degradation when fruit remains on the vine past its optimal maturation time.

\section{References}

1. C. D’Onofrio, F. Matarese, A. Cuzzola. J. Sci. Food Agric. 97, 2898-2907 (2017).

2. C. A. Black, M. Parker, T. E. Siebert, D. L. Capone, I. L. Francis. Aust. J. Grape Wine Res. 21, 582-600 (2015).

3. M. Parker, D. L. Capone, I. L. Francis, M. J. Herderich. J. Agric. Food Chem. 66, 2281-2286 (2018).

4. E. Nicolosi, A. Continella, A. Gentile, A. Cicala, F. Ferlito. Sci. Hort. 146, 1-6 (2012).

5. S. Poni, L. Casalini, F. Bernizzoni, S. Civardi, C. Intrieri. Am. J. Enol. Vitic. 57, 397-407 (2006).

6. M. P. Diago, B. Ayestarán, Z. Guadalupe, S. Poni, J. Tardáguila. Am. J. Enol. Vitic. 63, 367376 (2012).

7. M. Gatti, F. Bernizzoni, S. Civardi, S. Poni. Am. J. Enol. Vitic. 63, 325-332 (2012).

8. M. Sternad Lemut, P. Sivilotti, P. Franceschi, R. Wehrens, U. Vrhovsek. J. Agric. Food Chem. 61, 8976-8986 (2013).

9. C. Pastore, G. Allegro, G. Valentini, E. Muzzi, I. Filippetti. Sci. Hort. 218, 147-155 (2017).

10. K. Šuklje, G. Antalick, Z. Coetzee, L. M. Schmidtke, H. Baša Česnik, J. Brandt, W. J. du Toit, K. Lisjak, A. Deloire. Aust. J. Grape Wine Res. 20, 223-233 (2014).

11. H. Feng, P. A. Skinkis, M. C. Qian. Food Chem. 214, 736-744 (2017).

12. P. Sivilotti, R. Falchi, J. C. Herrera, B. Škvarč, L. Butinar, M. Sternad Lemut, M. Bubola, P. Sabbatini, K. Lisjak, A. Vanzo. J. Agric. Food Chem. 65, 8426-8434 (2017).

13. M. Alessandrini, F. Battista, A. Panighel, R. Flamini, D. Tomasi. J. Sci. Food Agric. 98, 1674-1684 (2018).
14. D. Bavčar, H. Baša Česnik, F. Čuš, F., T. Košmerl. Int. J. Food Sci. Technol. 46, 18011808 (2011).

15. D. Bavčar, H. Baša Česnik, F. Čuš, A. Vanzo, L. Gašperlin, T. Košmerl. S. Afr. J. Enol. Vitic. 32, 190-203 (2011).

16. P. Comuzzo, Marconi M., Zanella G., Querzè M. Food Chem. 264, 16-23 (2018).

17. T. Frioni, S. Zhuang, A. Palliotti, P. Sivilotti, R. Falchi, P. Sabbatini. Am. J. Enol. Vitic. 68, 325-335 (2017).

18. J. C. Herrera, B. Bucchetti, P. Sabbatini, P. Comuzzo, L. Zulini, A. Vecchione, E. Peterlunger, S. D. Castellarin, S.D. Aust. J. Grape Wine Res. 21, 254-265 (2015).

19. W. M. Kliewer, N. K. Dokoozlian. Am. J. Enol. Vitic. 56, 170-181 (2005).

20. S. Poni, M. Gatti. Acta Hort. 1188, 21-34 (2017).

21. K. Šuklje, H. Baša Česnik, L. Janeš, V. Kmecl, A. Vanzo, A. Deloire, P. Sivilotti, K. Lisjak. Int J. Sci. Vigne Vin. 47, 83-97 (2013).

22. H. Feng, F. Yuan, P. A. Skinkis, M. C. Qian. Food Chem. 173, 414-423 (2015).

23. A. Asproudi, M. Petrozziello, S. Cavalletto, S. Guidoni. Food Chem. 211, 947-956 (2016).

24. S. Savoi, D. C. J. Wong, A. Degu, J. C. Herrera, B. Bucchetti, E. Peterlunger, A. Fait, F. Mattivi, S. D. Castellarin, S.D. Frontiers Plant Sci. 8, 1124 (2017).

25. F. Matarese, G. Scalabrelli, C. D’Onofrio. Funct. Plant Biol. 40, 552-565 (2013).

26. M. Gil, R. Bottini, F. Berli, M. Pontin, M. F. Silva, P. Piccoli. Phytochemistry 96, 148-157 (2013).

27. E. Zhang, F. Chai, H. Zhang, S. Li, Z. Liang, P. Fan. Food Chem. 237, 379-389 (2017).

28. S. M. Bureau, R. L. Baumes, A. J. Razungles. J. Agric. Food Chem. 48, 1290-1297 (2000).

29. A. Verzera, G. Tripodi, G. Dima, C. Condurso, A. Scacco, F. Cincotta, D. M. L. Giglio, T. Santangelo, A. Sparacio, A. J. Sci. Food Agric. 96, 150-159 (2016). 